\title{
Nuevos datos sobre la Edad del Hierro en Alto Duero: el castro de El Pico (Cabrejas del Pinar, Soria)
}

\author{
New data on the Iron Age from the Upper Duero Valley: the hillfort of El Pico \\ (Cabrejas del Pinar, Soria)
}

Cristina Vega Maeso (*)
Eduardo Carmona Ballestero $(* *)$

\section{RESUMEN}

El trabajo presenta los datos derivados de una investigación arqueológica realizada en el castro de El Pico (Cabrejas del Pinar, Soria). El objetivo de la misma era valorar el registro arqueológico conservado y proporcionar una adscripción cronológica definida al yacimiento, que tradicionalmente se había vinculado a la "Cultura Castreña Soriana" de la Primera Edad del Hierro. Las nuevas evidencias han mostrado una discrepancia entre datos arqueológicos y fechas absolutas. La discusión al respecto ha permitido determinar una adscripción cronocultural diferente para El Pico, relacionándola con el grupo de manifestaciones arqueológicas que configuran el Celtibérico Antiguo (siglos VII-V a.C.). Los datos plantean nuevas vías de análisis en una zona donde confluyen dos conjuntos arqueológicos (los Castros Sorianos y las entidades arqueológicas del Celtibérico Antiguo) que se relacionan con un proceso histórico de transición hacia las sociedades estatales poco definido y escasamente tratado. ally has been related to the "Sorian Hillforts Culture" of the Early Iron Age. The documented evidence shows a discrepancy between archaeological data and absolute dates. That circumstance allows to us discuss and propose a new chrono-cultural definition to El Pico, that actually it is linked with that archaeological group of "Ancient Celtiberic" ( $7^{\text {th }}-5^{\text {th }}$ centuries $b$. C.). The data suggest new lines of analysis in a zone where there were two archaeological groups (the Sorian Hillforts and Ancient Celtiberian archaeological sites) tied to a poorly defined historical process of the emergence of state societies.

Palabras clave: Primeras cerámicas a torno; Desfase datación relativa y absoluta; Celtibérico; Península Ibérica.

Key words: Early wheel-turned ceramics; Discrepancy betweeen relative and absolute dating; Celtiberian culture; Iberian Peninsula.

\section{INTRODUCCIÓN Y PROBLEMÁTICA}

El castro de El Pico (Fig. 1) aparece habitualmente en las publicaciones sobre la Edad del Hierro del Alto Duero (Taracena Aguirre 1941; Romero Carnicero 1984a, 1984c; Bachiller Gil 1987; Romero Carnicero 1991; Bachiller Gil 1992; Jimeno Martínez y Arlegui Sánchez 1995; Romero Carnicero y Lorrio Alvarado 2011). Sin embargo, el conocimiento real del yacimiento es bastante reducido, ciñéndose, hasta ahora, a las evidencias superficiales: muralla con una torre, friso de piedras hincadas y restos cerámicos, que se extienden por un área triangular de 1,11 ha. Estos restos han constituido la base para la in-
Universidad de Cantabria. Avda. de los Castros s/n. 39005 Santander. España. Correo e.: cvegamaeso@gmail.com

(**) Área de Arqueología, Facultad de Humanidades, Universidad de Burgos. C/ Villadiego s/n. 09001 Burgos. España. Correo e.: educarmonaball@gmail.com

Recibido: 22-VI-2012; aceptado 26-IX-2012. 
clusión del yacimiento dentro del grupo de los "Castros Sorianos" de la Primera Edad del Hierro con una fase final de ocupación 'celtiberizada'. Tal afirmación se basa en la presencia tanto de cerámica a mano de cocción reductora y restos a torno celtibéricos recogidos en sucesivas visitas al yacimiento como en la presencia del friso de piedras hincadas (Romero Carnicero 1991: 63; Lerín Sanz 1999). Estas mismas evidencias, junto a las características de las fortificaciones (muralla acodada y torre), sustentan opiniones que discrepan de la anterior propuesta y consideran El Pico un hábitat más moderno, cuya ocupación se ceñiría a la Segunda Edad del Hierro (Bachiller Gil 1992: 18; Bachiller Gil y Ramírez Sánchez 1993: 40; Jimeno Martínez y Arlegui Sánchez 1995: 113, 115 y 120; Jimeno Martínez 2011: 248), en sintonía con una propuesta anterior de Taracena (1954: 226-27), quien habla de una línea de castella de vigilancia en las Sierras de Frentes y Cabrejas en los inicios del Hierro II (siglos IV-III a.C.). Las alternativas señaladas no solo remiten a la delimitación cronocultural de las evidencias, sino que ambas tienen implicaciones que inciden en la manera de entender el proceso de "celtiberización" del norte de Soria.

La información existente hasta el momento resultaba contradictora y no se estaba en disposición de contrastar de manera concluyente ninguna de las dos hipótesis. En este trabajo presentamos los resultados de la intervención realizada en el castro de El Pico. Su objetivo era ponderar el alcance de las agresiones que había

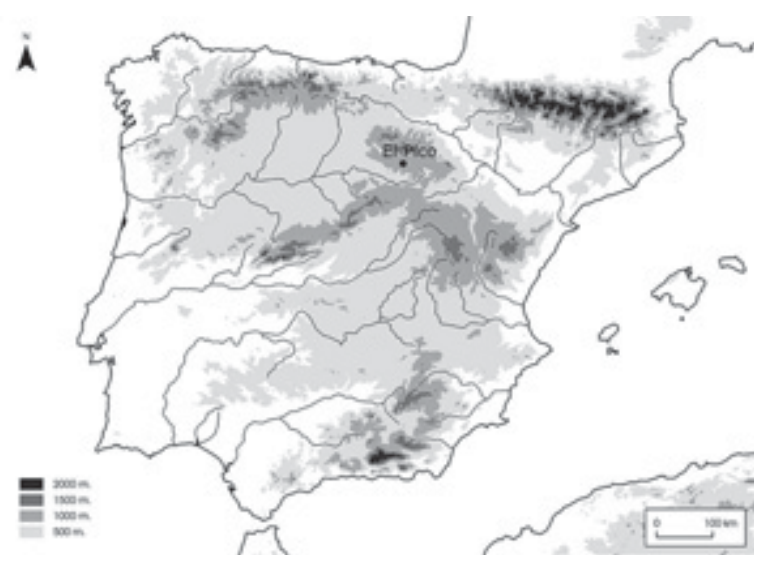

Fig. 1. Localización del castro de El Pico (Cabrejas del Pinar, Soria) en la Península Ibérica. sufrido el yacimiento durante las últimas décadas $\mathrm{y}$, sobre todo, documentar su atribución cultural y adscripción cronológica. El registro arqueológico contextualizado que ha aportado permite contrastar las distintas hipótesis existentes sobre el yacimiento $\mathrm{y}$, además, discutir el proceso de "celtiberización" en la zona.

\section{MARCO ARQUEOLÓGICO DE REFERENCIA PARA EL CASTRO DE EL PICO}

La investigación sobre la Edad del Hierro en el norte de Soria tiene dos marcos de referencia paradigmáticos: el conjunto de castros y poblados del Alto Duero (siglos VII-IV a.C.) y la 'celtiberización' del norte de Soria (siglos IV-III a.C.). Ambos se basan en argumentos arqueológicos descriptivos, utilizando determinados fósiles-directores como elementos clasificatorios.

Los castros y poblados del Alto Duero se vinculan a la Primera Edad del Hierro. Taracena (1941) los definió como "cultura castreña soriana" y sus trabajos siguen siendo referentes fundamentales. Incluso su cronología, entre el siglo VII y mediados del IV a.C., es aceptada por la mayoría de los investigadores (Romero Carnicero 1984a; Jimeno Martínez 1985; Romero Carnicero 1991; García-Soto Mateos y Rosa Municio 1995; Lorrio 1997: 268-270; Romero Carnicero 2005) y las dataciones radiocarbónicas disponibles parecen confirmarla (Eiroa García 1979, 1980, 1984-1985; Romero Carnicero 1991, 1999; Romero Carnicero y Lorrio Alvarado 2011).

Forman el grupo emplazamientos en altura con defensas monumentales (murallas reforzadas con fosos, torres y/o barreras de piedras hincadas), que configuran hábitats castreños de reducidas dimensiones, pues raramente superan las 1,5 ha (Romero Carnicero 1984a; Jimeno Martínez 1985; Romero Carnicero 1991; Lorrio 1997: 268). Su articulación interna se conoce poco. Se reduce a la documentación de cabañas de distinta morfología y técnica constructiva (Romero Carnicero 1984a, 1984b; Romero Carnicero y Misiego Tejada 1995: 72; Romero Carnicero 1999: 153-54). En las excavaciones aparece, sobre todo, cerámica a mano, cuya tipología ha sido definida ampliamente por Romero Carnicero (1984a, 1991) y es el principal 
fósil-director junto a los frisos de piedras hincadas. Este parco registro incluye una metalurgia mayoritariamente en bronce, vinculada a adornos y armas (Romero 1991: 303 y 323), y unos medios técnicos de producción no especializados de tradición prehistórica como utillaje sobre láminas de sílex, hachas pulimentadas y molinos barquiformes (Bachiller Gil 1988-1989; Romero Carnicero 1991: 303-05). La información sobre los aspectos económicos es escasa. A pesar de ello, se supone una dedicación preferente a la ganadería (Jimeno Martínez 1985; Romero Carnicero y Misiego Tejada 1995: 73), complementada con la agricultura y la caza, a la luz de la presencia de especies cinegéticas en los yacimientos (Bellver Garrido 1992; Liesau y Blasco 1999).

Paralelamente al desarrollo de estos castros, se reconocen en la llanura aluvial soriana las primeras necrópolis de incineración y poblados que se ubican también en altura y son de tamaño algo mayor. La mayoría de estos hábitats se han documentado en prospecciones y se conocen mal. Ello ha provocado una disparidad entre quienes los incluyen en el grupo de los castros (García-Soto Mateos y Rosa Municio 1995: 84-86; Romero Carnicero y Misiego Tejada 1995: 72) y quienes les individualizan como un conjunto distinto relacionado con las manifestaciones arqueológicas del Alto Tajo-Alto Jalón (Revilla Andia y Jimeno Martínez 1986-87; Jimeno Martínez y Arlegui Sánchez 1995; Lorrio 1997; Romero Carnicero y Lorrio Alvarado 2011: 114-118). Investigaciones recientes en la zona norteña abundan en la polémica al reconocerse fortificaciones en un buen número de estos poblados (Alfaro 2005) y necrópolis (Tabernero et al. 2010).

El segundo marco de referencia para el estudio del castro de El Pico se relaciona con el proceso histórico denominado "celtiberización". En la zona norte de Soria se ha relacionado con cambios en el registro arqueológico. El primero es el abandono de la mayoría de los castros del Primer Hierro, manteniéndose en algunos la ocupación 'celtiberizada'. Esto coincide con la aparición de poblados de nueva planta (Romero Carnicero 1991; Bachiller Gil 1992; Bachiller Gil y Ramírez Sánchez 1993; Lorrio 1997), emplazados preferentemente en cerros destacados sobre amplias llanuras. Ello, unido a la configuración de la cabaña ganadera (Liesau y Blasco 1999), permite inferir una reorientación de los modelos de producción hacia una agricultura extensiva de cereal. La excavación de alguno de estos poblados ha constatado su organización conforme a un modelo radial, cerrado con una muralla, que sirve de muro trasero a las viviendas. Este modelo es compartido por numerosos castros y poblados del Alto Tajo-Alto Jalón e, incluso, del Ebro (Martínez Naranjo 1997: 174; Ortega 1999: 426-28; Cerdeño y Juez 2002). Una segunda novedad es la cerámica a torno, principal referente discriminatorio, que enlaza con la recepción de piezas foráneas con clara influencia ibérica (Jimeno Martínez y Arlegui Sánchez 1995: 120). Con el tiempo la transferencia tecnológica se concretará en la adopción local del torno de alfarero, el horno oxidante y la pintura ornamental en las cerámicas (Jimeno Martínez 1985). No está claro cuando se produce esa adopción, lo que es de lamentar no tanto por el impacto que pudo suponer en las comunidades locales, cuanto por la intensa utilización de las piezas torneadas como fósiles-guía de la "celtiberización". Como fecha estándar se toma un momento a caballo entre el siglo IV y el III a.C. (Lorrio 1997; Sanz Mínguez 1997: 277-280; Escudero Navarro y Sanz Míngez 1999). Las piezas a torno encontradas en contextos más antiguos se consideran importaciones procedentes de ámbitos ibéricos (Arenas 1999; Cerdeño et al. 1999). Esa situación es habitual en castros del Alto Tajo-Alto Jalón como El Turmielo, El Palomar o El Ceremeño (Arenas 1999; Cerdeño y Juez 2002). La tercera novedad es el desarrollo significativo de la metalurgia y, principalmente, del trabajo del hierro y bronce (Lorrio 1997), que nutre de un buen número de objetos sobre todo a las necrópolis. En ellas se reconocen armas y adornos, que se relacionan con la demanda de bienes de prestigio consumidos por un grupo de privilegiados, asociado con los guerreros, por la significación de los elementos militares en el registro.

No hay muchos más datos sobre la 'celtiberización' en torno a la serranía soriana pero es indudable que ya en el siglo III a.C. el proceso ha culminado. Su expresión más evidente sería la configuración de los primeros oppida, como Numancia, Tiermes o Uxama. En proceso de sinecismo concentran el poblamiento en su entorno y articulan territorios políticos ya claramente jerarquizados. Incluyen asentamientos de mediano tamaño y castella que controlan los territorios

Trab. Prehist., 70, N. ${ }^{\circ}$ 2, julio-diciembre 2013, pp. 372-384, ISSN: 0082-5638

doi: $10.3989 /$ tp.2013.12120 
fronterizos. Este tipo de organización territorial es ejemplo de un tipo de formación social clasista que se suele relacionar con la etnia de los arévacos (Bachiller Gil 1992; Burillo Mozota 2007: 228-234).

\section{INTERVENCIÓN ARQUEOLÓGICA EN EL PICO}

\subsection{Metodología de prospección y excavación}

Las acciones que han afectado de manera negativa al castro de El Pico en las últimas décadas llevaron al Servicio Territorial de Cultura de Soria a promover una actuación arqueológica de urgencia durante 2009. Su objetivo era doble: valorar el alcance de tales afecciones y documentar el potencial arqueológico del castro. Bajo estas premisas se articuló un programa en varias fases. La primera consistió en una prospección sistemática e intensiva para reconocer y documentar las evidencias arqueológicas superficiales. Los métodos de reconocimiento aplicados (teledetección a través de ortoimágenes e inspección directa del terreno) documentaron evidencias de distinta naturaleza que delimitaron el yacimiento con claridad. El levantamiento topográfico posterior registró la primera planimetría del yacimiento $\mathrm{y}$ de los vestigios detectados en superficie. En la segunda fase se excavaron 3 sondeos de $3 \mathrm{x}$ $2 \mathrm{~m}$, abiertos en diferentes ámbitos del yacimiento (Fig. 2): el extremo norte, la zona central y las inmediaciones de la muralla. Se siguieron las pautas metodológicas de Harris (1991) y Carandini (1997) sobre las evidencias estratigráficas y sus relaciones. El trabajo se completó con el estudio macroscópico de los materiales cuyas características se integraron en una base de datos en la que se recogieron sus atributos técnicos y tipológicos significativos.

El yacimiento se ubica en un espigón orientado al norte de la Sierra de Cabrejas. La sierra discurre en sentido E-O y es el límite natural entre la zona septentrional y meridional de Soria. Atraviesan la sierra varios vallejos (río Muriel, arroyo de la Hoz...) que son pasos naturales de acceso en sentido N-S. Precisamente, en la entrada norte al estrecho valle del arroyo de la $\mathrm{Hoz}$ se sitúa el espigón del castro de El Pico. Es una pequeña meseta, delimitada por unos bordes escarpados al Norte, que se van suavizando hacia el Sur.

Los métodos de documentación arqueológica identificaron un área triangular delimitada en dos de sus flancos por cortados rocosos y cerrada al sureste por una muralla. Ya Taracena (1941: 45) dio cuenta de las características principales de esta estructura: $68 \mathrm{~m}$ de largo aproximadamente, construida a base de canto seco de pequeño tamaño y reforzada por un friso de piedras hincadas con deficiente estado de conservación. Un pequeño pasillo separa ambas estructuras. Taracena Aguirre (1941: 45) señala una posible torre en el flanco oeste de la muralla. La más que notoria acumulación de material constructivo (más de $20 \mathrm{~m}$ de anchura y casi $5 \mathrm{~m}$ de altura) en este punto (Fig. 2) avala la hipótesis. A la luz de la distribución de los elementos defensivos habría un único acceso al recinto que obligaría a recorrer el pasillo entre la línea de muralla y la de piedras hincadas hasta un hueco localizado en el extremo occidental de la muralla, al borde mismo del precipicio (Romero Carnicero 1991: 62).

La excavación de los tres sondeos ha deparado diferentes resultados. En el Sondeo 1 la secuencia estratigráfica revela una antigua construcción de adobe derruida (UE2) sobre restos cenicientos de color oscuro con gran cantidad

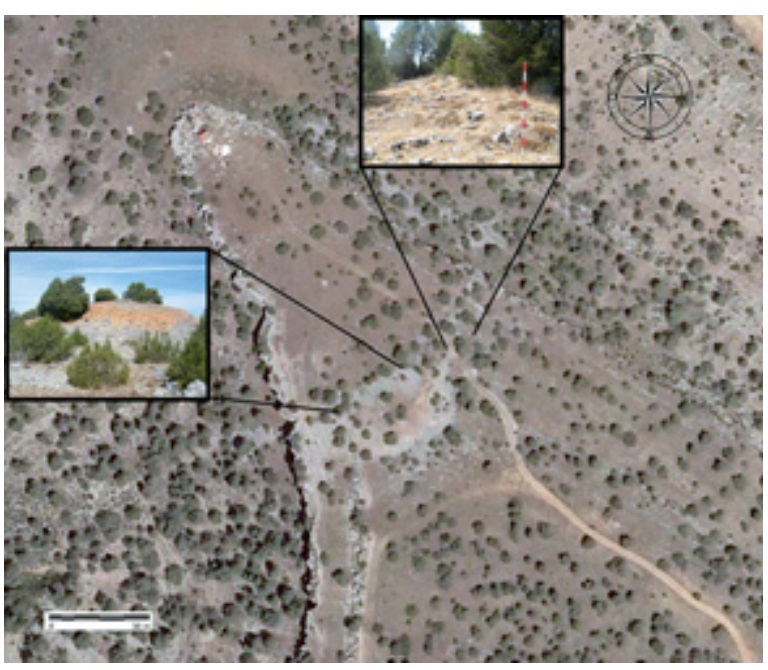

Fig. 2. Correspondencia entre las evidencias observables en la ortofoto [PNOA_CYL_NE_2009_25cm_OF_ rgb_etrs_hu30_h05_0349_1-3.tif] del castro de El Pico (Cabrejas del Pinar, Soria) y los elementos defensivos (muralla y torre). 
de material arqueológico (UE3). Todo ello está cubierto por una unidad (UE1) formada por acumulación de cantos calizos, quizá provenientes del arrastre de los materiales de las estructuras (torre, muralla, ¿cabañas?) situadas en la parte más alta del cerro. En el Sondeo 2, en su mitad norte, se localizó una secuencia de 7 unidades estratigráficas (Fig. 3). Todas cubrían a un pequeño zócalo de piedras calizas (UE5) que aprovecha un corte en el terreno natural para su construcción. Parece haber sido la base de un muro de una cabaña construida con paredes de adobe. De ella se conserva un echadizo (UE4) constituido por arcilla muy compacta de coloración rojiza, que puede ser un resto del antiguo suelo. Esta cabaña sufrió un incendio, cuyo testimonio son las potentes cenizas (UE3) de color negro que cubren a la UE4. El fuego destruyó la cabaña, tal y como refleja el derrumbe de los tabiques de adobe (UE2), que sellaron el acontecimiento. Como en el Sondeo 1, la secuencia se cierra con una acumulación de material (UE1) cuya génesis es el desmantelamiento de las unidades más altas del yacimiento. El Sondeo 3 es el menos significativo. No conserva más que el nivel superficial (UE1) con materiales de épocas diversas, aunque mayoritariamente protohistóricos. El grado de rodamiento de ciertas piezas indica la posible erosión a la que se ha visto sometido el yacimiento en este lugar. El único contexto se documentó en la edificación de morfología rectangular del Sondeo 2. En su interior se han recuperado objetos domésticos (cerámica común, molino, etc). Su concentración y particular asociación remiten con bastante probabilidad a un espacio de almacenaje o despensa, por comparación con otros yacimientos donde se aprecia una articulación interna de los espacios domésticos bastante estandarizada (Cerdeño y Juez 2002: 34-44; Valdés 2002).

El análisis de la estratigrafía de los sondeos permite distinguir tres fases o periodos: Fase 1 o de ocupación, en ella se incluyen las unidades interpretadas como parte de un suelo y los restos de la pared de una cabaña en el Sondeo 2; Fase 2 , que representarían un episodio de incendio que se reconoce en distintos lugares del poblado; por último, una Fase 3, de abandono del recinto, representada en las UUEE 1 de los tres sondeos.

\subsection{La cerámica}

En El Pico se han recuperado algo más de 350 piezas cerámicas, que constituyen el elemento arqueológico más abundante. Los fragmentos se pueden agrupar en 233 familias, o casos, divididas en función de su manufactura a mano y a torno ( $89 \%$ del total). Los datos técnicos de las piezas revelan que la mayoría se realizaron en atmósferas controladas, reductoras (116 casos) u oxidantes (71 casos). Ello requiere unos conocimientos técnicos importantes, que se vinculan fundamentalmente a los hornos empleados. El tipo de manufactura matiza estos datos, en varios aspectos llamativos. La cerámica a mano (25 ca-

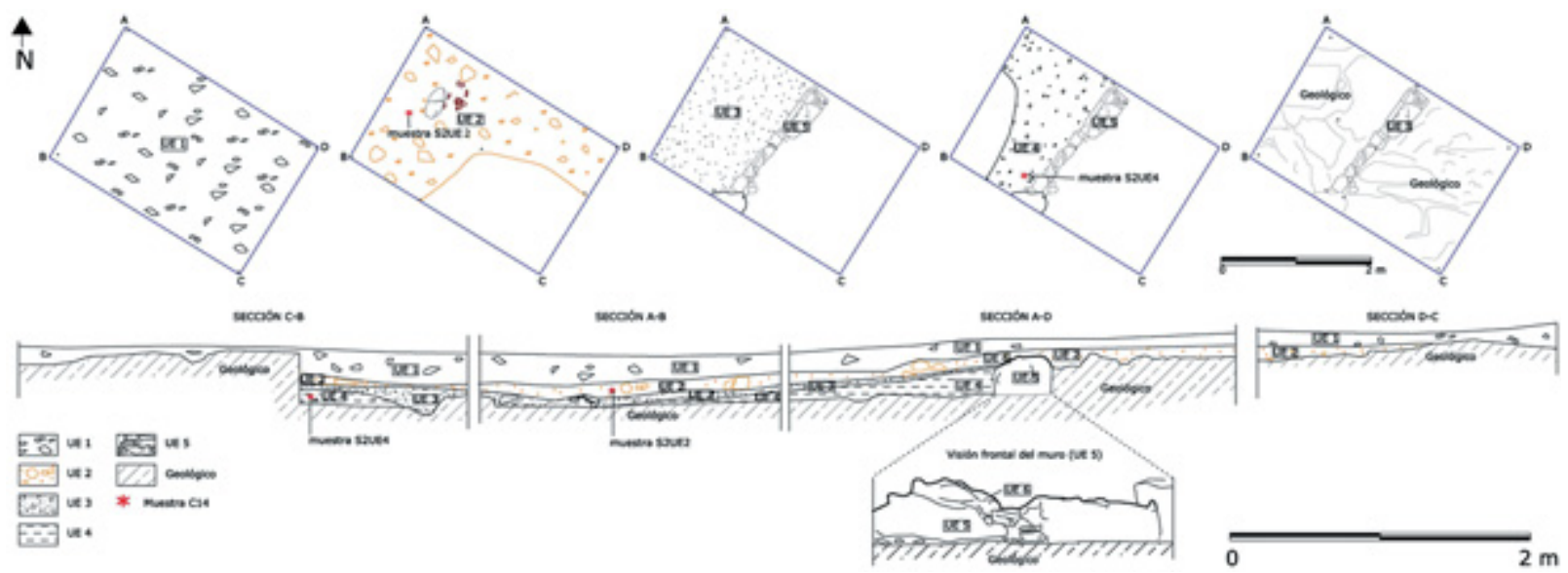

Fig. 3. Plantas y secciones del Sondeo 2 de El Pico (Cabrejas del Pinar, Soria). UE Unidad Estratigráfica.

Trab. Prehist., 70, N. ${ }^{\circ}$ 2, julio-diciembre 2013, pp. 372-384, ISSN: 0082-5638

doi: $10.3989 /$ tp.2013.12120 
sos) suele ser de cocción reductora (18 casos), con pastas oscuras y acabados en su mayoría bruñidos (17 casos), habituales en este tipo de contextos. También las 208 piezas a torno se han cocido, en general, en ambientes reductores (98 casos), adquiriendo unos tonos que las incorporan al grupo de los recipientes de pastas grises, normalmente considerados de uso "común". Además hay ejemplares oxidantes (67 casos) o mixtos (37 casos) de tonos anaranjados y ocres.

La observación macroscópica de las inclusiones confirma las producciones a mano y a torno. En las primeras las pastas presentan una mayoría de inclusiones cuarcíticas (18 casos), de tamaño usualmente medio y ordenación irregular. En las pastas de los ejemplares a torno, son mayoritarias las micas (71 casos), combinadas o no con arenas cuarcíticas (103 casos), de tamaño fino y ordenación equilibrada. No puede estimarse el alcance de esta particularidad por lo limitado de la intervención. En otros contextos se ha propuesto relacionar ambas secuencias de fabricación con una esfera doméstica, a mano, realizada por mujeres y ceñida a recipientes de uso común, y otra especializada, a torno, a cargo de artesanos y que abarca todo el elenco de recipientes (Escudero Navarro 1999: 252). Sea esta hipótesis correcta o no, sí estamos de acuerdo en que la producción de cerámica a torno de características estandarizadas exige un contexto productivo especializado, donde se reconocen por primera vez verdaderos talleres de alcance local (Escudero Navarro 1999; García Heras 1999; Burillo et al. 2008).

Desde el punto de vista morfológico, la muestra recuperada es poco numerosa, pero significativa (Fig. 4). Las piezas a mano son poco elocuentes (2009/78/S2/3/1 y 2009/78/S2/2/5), pero las torneadas admiten un análisis un poco más exhaustivo. Aparecen bordes de "pico de pato, cisne o ánade" (2009/78/S2/1/7, 2009/78/S2/2/16 y 18) y fondos rehundidos (2009/78/S2/2/6 y 7), frecuentes en contextos celtibéricos (Sacristán de Lama 1986; Lorrio 1997; Cerdeño y Juez 2002). Junto a ellas aparece un asa bilobulada de desarrollo corto $(2009 / 78 / \mathrm{S} 2 / 1 / 8)$ que, por sus paralelos (Ruiz y Molinos 1992: 60, 65, 72; Cerdeño y Juez 2002: 72), bien pudiera pertenecer a un recipiente de almacenamiento. En el conjunto no se reconocen las características decoraciones geométricas pintadas. La ausencia de ornamentación y los tonos mayoritariamente grisáceos de las pas-
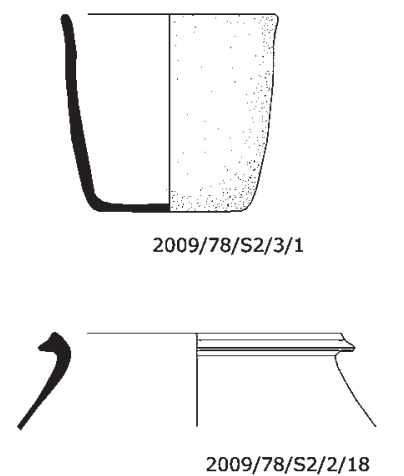

$2009 / 78 / \mathrm{S} 2 / 2 / 18$

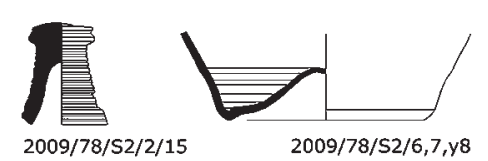

$2009 / 78 / 52 / 1 / 8$
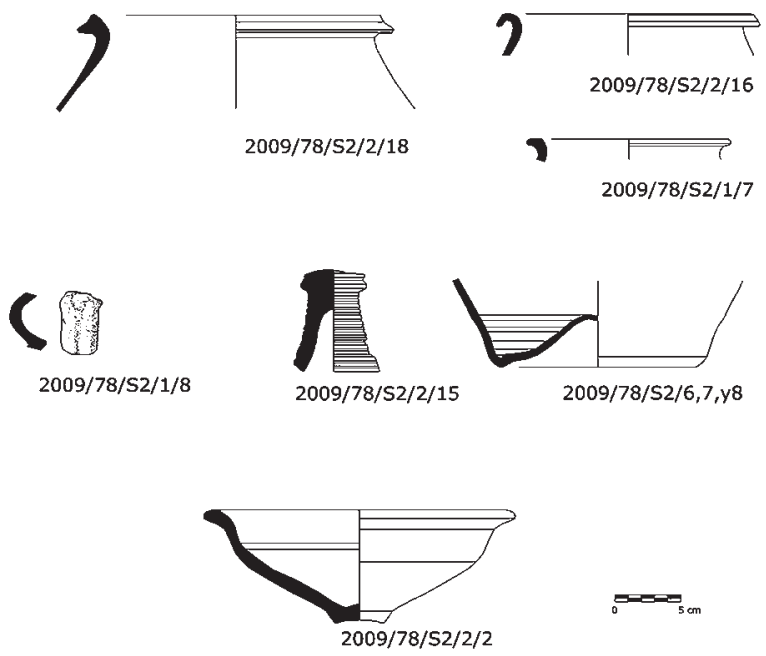

$2009 / 78 / 52 / 1 / 7$

$09 / 78 / 52 / 6,7, y 8$

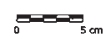

Fig. 4. Castro de El Pico (Cabrejas del Pinar, Soria). Cerámicas a mano (arriba) y torneadas: bordes de 'pico de pato', asa bilobulada, tronco de copa, fondo rehundido y plato.

tas determinan que los recipientes documentados se pueden integrar dentro del genérico epígrafe de cerámica celtibérica "común" o "de cocina", en sus dos modalidades, a mano y a torno, cuyos tipos más frecuentes son los vasos a mano y las ollas de morfologías abombadas (Sacristán de Lama 1986: 194-200; Lorrio 1997: 242; Sanz Mínguez 1997: 307-308). En definitiva, morfologías que se pueden vincular al ámbito doméstico.

Destacamos dos recipientes singulares: un plato completo y un tronco de copa. El plato (2009/78/S2/2/2) es de borde exvasado y base ligeramente umbilicada. El tipo tiene una larga tradición en el sur y levante de la Península Ibérica y su origen se suele remontar a ciertos cuencos o platos abiertos de pastas grises cuyo génesis se reconoce en tipos foráneos, fenicios o focenses (Barrio y Blasco 1989: 235; Ruiz y Molinos 1992: 37-40, 66; Schubart 2002-03). En el ámbito celtibérico se fija su presencia en torno a la segunda mitad del siglo VI a.C. como vaji- 
lla de mesa, importada desde contextos ibéricos levantinos (Arenas 1999: 302). El fuste o tronco de copa está decorado con incisiones profundas, que le confieren un aspecto estriado (2009/78/ $\mathrm{S} 2 / 2 / 15)$. Es un tipo habitual en contextos del Celtibérico Pleno y Tardío (Sacristán de Lama 1986: 172-73; Amaré Tafalla y Aguarod Otal 1987; Sanz Mínguez 1997: 289; Mañanes Pérez 2002: 94-95, lám XLII; Burillo et al. 2008: 187, fig. 7). Se fecha entre los siglos III y I a.C. En consecuencia, las características generales del conjunto lo sitúan en un momento avanzado de la Segunda Edad del Hierro.

\subsection{Otros restos}

Los restos faunísticos se han recuperado en cantidad mínima (NR: 26), lo que unido a la posición estratigráfica de la mayoría de ellos (Sondeo 3, UE 1), ha lastrado su análisis. Se han identificado bovinos (NR: 14), ovicaprinos (NR: 2) y aves (NR: 1). La principal aportación corresponde a los huesos procedentes del Sondeo 2 por su papel en la datación absoluta.

La documentación de restos de molinos barquiformes ha resultado interesante. Destacamos el recuperado en el Sondeo 2, asociado a una concentración de cerámica que incluía fragmentos de ollas de gran tamaño, que estaban entre los mejor conservados.

Durante la prospección y la excavación se han hallado numerosos trozos de adobe que podemos relacionar con los derrumbes de la parte superior de los muros de las viviendas. Muchos están muy alterados por fuego.

\section{DATACIONES RADIOCARBÓNICAS DE EL PICO}

La escasez de materiales arqueológicos recuperados exigía completar la datación basada en el estudio tecno-tipológico con métodos analíticos más precisos. Para ello, fueron seleccionados del Sondeo 2 una falange (UE2, 2009/78/S2/2/147) y un fémur (UE4, 2009/78/S2/4/1), ambos de ovicaprino. Se intentaba determinar el momento de ocupación de la cabaña (UE4) y el de su destrucción o abandono (UE2).
Se dataron por $A M S$ en el Poznan Radiocarbon Laboratory y se calibraron con el programa Oxcal v.4.1.5 (Bronk Ramsey 2010) (Tab. 1, Fig. 5). Señalamos, en primer lugar, que las fechas manifiestan la problemática relacionada con la denominada "catástrofe de la Edad del Hierro" (Rubinos et al. 1999: 149). Este término alude al efecto provocado por el desarrollo amesetado de la curva de calibración en el tramo 800 a 400 cal BC (Reimer et al. 2009). Tal circunstancia conlleva la obtención de intervalos calibrados particularmente amplios, incluso cuando la desviación típica es relativamente pequeña, como en El Pico. La meseta afecta en especial a la determinación obtenida en la UE4, cuya distribución de la edad calibrada se extiende en un intervalo de gran amplitud (784-511 cal BC). Esta misma meseta provoca el solapamiento parcial de las fechas calibradas, lo que dificulta determinar su sincronía o diacronía. $\mathrm{Su}$ respectiva posición estratigráfica que las vincula a episodios diacrónicos claramente definidos plantea un tiempo probable de separación entre ellas que parece coherente. Lamentablemente no se puede determinar con claridad el rango de esa diacronía.

La segunda valoración de las fechas de El Pico atiende a su interpretación y se refiere a su antigüedad respecto a los materiales arqueológicos. $\mathrm{Si}$ bien aparece alguna forma cerámica simple realizada a mano, la mayor parte del repertorio son recipientes a torno, entre ellos un pie de copa estriado con una datación relativa del Celtibérico Pleno (siglos IV-I a.C.). El desfase es evidente. En todo caso, el rango cronológico encaja mejor con las dataciones obtenidas en la fase inicial de los "Castros Sorianos" de la I Edad del Hierro (Fig. 5).

Siguiendo a Vega Toscano (2002: 127), consideramos las fechas desde un punto de vista crítico, alejándonos del uso mecánico que solo contempla confirmar las derivadas de los métodos tradicionales. Evitamos, así, caer en el error de desechar directamente la validez de las fechas obtenidas por contradecir la datación con técnicas tradicionales. Excluimos que haya un error en la datación pues los huesos estaban en contextos primarios. Además, al ser muestras de vida corta, los resultados son mas fiables que si, p. ej., se hubiera fechado carbón. Por otro lado, no se reconoció ninguna alteración postdeposicional que hiciera pensar que pudieran estar contaminadas ni se reconocieron

Trab. Prehist., 70, N. ${ }^{\circ}$ 2, julio-diciembre 2013, pp. 372-384, ISSN: 0082-5638

doi: $10.3989 /$ tp.2013.12120 


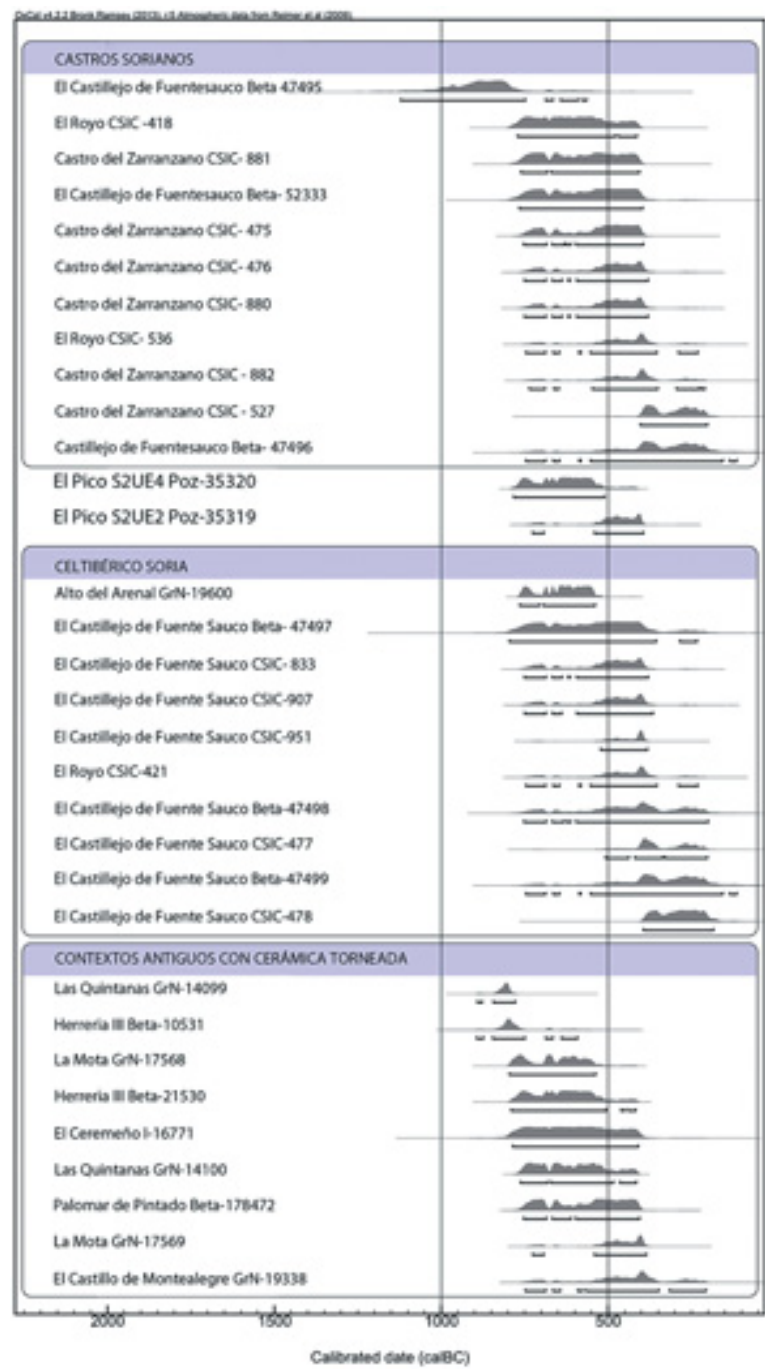

Fig. 5. Secuencia de fechas radiocarbónicas comentadas en el texto (Romero Carnicero 1991: 356; Seco Villar y Treceño Losada 1993: 137; Gómez Pérez y Sanz Mínguez 1993: 368; Heredero García 1993: 300; Romero Carnicero 1999: 162, 477; Cerdeño y Juez 2002: 40-41; Pereira Sieso et al. 2003: 163; Cerdeño 2008: 102) y situación de las nuevas fechas de El Pico (Cabrejas del Pinar, Soria) (Reimer et al. 2009; Bronk Ramsey 2010). alteraciones de la secuencia estratigráfica, como hoyos o zanjas, que permitieran suponer movimientos en vertical de materiales.

En este sentido, la comparación con los contextos datados por radiocarbono considerados "celtibéricos" remarca la antigüedad determinada para El Pico (Fig. 5). Prácticamente todas las fechas se sitúan en momentos más modernos, encuadrables sin ninguna duda en la Segunda Edad del Hierro. Otras se acercan bastante a la disponible para la UE2 e, incluso, la superan, como las del Castillejo de Fuentesaúco. Particular es la fecha del Alto del Arenal en San Leonardo de Yagüe. Como las de El Pico, remite a momentos bastantes antiguos y las evidencias asociadas son de atribución celtibérica. Por esta razón, ha sido considerada en alguna ocasión como prueba de una ocupación "castreña" anterior, aun sin los correspondientes materiales (Romero Carnicero 1999).

Las fechas dejan de ser tan inusuales si las comparamos con otras de zonas anejas al ámbito soriano (Fig. 5) que sitúan las cerámicas torneadas en momentos bastante antiguos. Proceden del centro de la Cuenca del Duero: dos de La Mota en Medina del Campo (vivienda con cerámicas a torno), una del Castillo de Montealegre (celtibérico) y dos de Las Quintanas que los excavadores descartaron por incoherentes debido a su antigüedad. Otra se localiza en el ámbito carpetano, concretamente en la tumba 62 de la necrópolis de Palomar del Pintado (Villafranca de los Caballeros, Toledo) en cuyo ajuar aparece un plato del mismo tipo que el recuperado en la UE3 de la cabaña de El Pico. Además, en el castro celtibérico de El Ceremeño las determinaciones obtenidas para el nivel inferior son prácticamente idénticas a las de El Pico. Fechan viviendas con cerámica a mano y a torno con formas semejantes a las recuperadas en El Pico (Cerdeño y Juez 2002: 63-84). Finalmente, las dataciones de la necrópolis asociada de Herrería III también son equiparables a las obtenidas en El Pico.

\begin{tabular}{|c|c|c|c|c|c|}
\hline ID & Fecha B.P. & Calibración 2 & Observación & Muestra & Contexto \\
\hline Poz-35319 & $2390 \pm 30$ & $\begin{array}{lrr}726 & (5,5 \%) & 693 \\
541 & (89,9 \%) & 395\end{array}$ & $2,1 \% \mathrm{~N} 6,7 \% \mathrm{C}$ & Hueso & Cabaña, UE 2 \\
\hline Poz- 35320 & $2495 \pm 30$ & $784(95,4 \%) 511$ & $2,4 \% \mathrm{~N} 7,5 \% \mathrm{C}$ & Hueso & Cabaña, UE 4 \\
\hline
\end{tabular}

Tab. 1. Dataciones absolutas obtenidas en El Pico (Cabrejas del Pinar, Soria). 
En consecuencia, los datos reunidos abogan por la verosimilitud de las dataciones obtenidas, las cuales plantean un escenario, que no encaja con el marco arqueológico de referencia ya descrito.

\section{DISCUSIÓN: LAS EVIDENCIAS DE EL PICO EN EL MARCO DE LA "CELTIBERIZACIÓN" DE LA SERRANÍA SORIANA}

La información recuperada en El Pico plantea una discrepancia respecto al panorama arqueológico tradicional por la discordancia entre la datación relativa proporcionada por los materiales arqueológicos y la absoluta, obtenida mediante $A M S$. Se impone una valoración crítica de la información recuperada. El caso remite a un debate de mayor calado sobre la correlación de la cronología proporcionada por los fósiles-directores y las determinaciones obtenidas por medios analíticos. El recurso a fósiles-directores, como la cerámica torneada en el centro de la Península Ibérica, para la fijación de cronologías está sujeto a problemas importantes si se utiliza de manera mecánica, como ya hemos visto. En este marco, la presencia de materiales torneados en un hábitat fortificado con unas fechas antiguas necesita una explicación.

Una hipótesis, plausible, vincula los hallazgos con importaciones del área ibérica en yacimientos de la Cuenca del Duero (1) o en el Alto Tajo-Alto Jalón (Martínez Naranjo 1997: 175; Arenas 1999; Cerdeño et al. 1999). Normalmente se trata de unas producciones de pastas claras, amarillentas o rojizas, con pintura roja vinosa dispuesta en gruesas bandas horizontales o círculos concéntricos. El repertorio cerámico esperado se correspondería con una mayoría de recipientes a mano entre los que se pudieran reconocer elementos torneados, que serían los importados, como en El Turmielo (Martínez Naranjo 1997: 175). Como esta situación no se da en El Pico, la explicación debe ser otra.

Otra posibilidad es que las dataciones se relacionen con una "celtiberización" más antigua de

(1) Blanco González, A. 2009: El poblamiento del Bronce Final y Primer Hierro en el sector meridional de la Submeseta Norte. Tesis doctoral inédita. Universidad de Salamanca. lo que se pensaba para este sector del Alto Duero. Esta hipótesis no sería descabellada puesto que se ha establecido un punto de arranque para tal fenómeno a fines del siglo VII a.C. a partir de las necrópolis del grupo Alto Duero-Alto Jalón (Cerdeño y García Huerta 2001; Lorrio Alvarado 2002) y, recientenemente, de los poblados del sur de Soria coetáneos a los castros de la serranía (Romero Carnicero y Lorrio Alvarado 2011: 114118). El caso particular de El Pico remite a una cabaña fechada en el hiato 784-395 cal BC. Por tales fechas es altamente probable que se relacione con el horizonte denominado Celtibérico Antiguo (siglo VII-mediados del V cal a.C.), que en su fase B incorpora ya elementos torneados (Martínez Naranjo 1997: 175; Cerdeño Serrano 1999; Jimeno Martínez y Martínez Navarro 1999; Ruiz Zapatero y Lorrio Alvarado 1999; Cerdeño y Juez 2002; López Ambite 2007). Este horizonte se vincula a determinados fenómenos del sector oriental de la Meseta donde la dinámica histórica se materializa en la generalización de los repertorios torneados, las necrópolis de incineración y la metalurgia del hierro, así como en las novedades en los patrones de asentamiento. A pesar de la reiterada presencia de objetos a torno en estos contextos, siguen siendo considerados importaciones. Las dudas respecto a su interpretación como tales en El Pico, ya se han planteado para otros repertorios de esta misma cronología (Cerdeño et al. 1995: 165-167).

El aspecto más importante expuesto por la investigación es la coexistencia en un espacio aledaño de evidencias arqueológicas atribuibles a los "castros sorianos" y de otras que poco tienen que ver con este grupo. El registro arqueológico recuperado en El Pico se puede asimilar al conjunto de manifestaciones arqueológicas del Alto Duero-Tajo-Jalón, muy relacionado con otras semejantes del valle del Ebro (Burillo y Ortega 1999: 131). La coetaneidad de las dataciones de los castros sorianos y de El Pico, así como sus divergencias en los aspectos materiales apuntan en esta dirección, es decir, en el reconocimiento de dos conjuntos arqueológicos sincrónicos y diferenciados cuyo límite parece la Sierra de Frentes y Cabrejas. Si admitimos esta hipótesis, el emplazamiento de El Pico adquiere una dimensión distinta. Su campo visual orientado al Norte, vigilando la amplia llanada que discurre entre la Sierra de Cabrejas y los Picos de Urbión, y su

Trab. Prehist., 70, N. ${ }^{\circ}$ 2, julio-diciembre 2013, pp. 372-384, ISSN: 0082-5638

doi: $10.3989 /$ tp.2013.12120 
ubicación al norte del valle del arroyo de la $\mathrm{Hoz}$ permite el control efectivo del acceso en sentido Norte-Sur. Este emplazamiento se relaciona con el Alto del Arenal de San Leonardo en esta misma situación. El exiguo registro documentado de momento en El Pico limita la articulación de hipótesis, si se quiere evitar el riesgo de especular, pero los datos hacen plausible que forme, junto al Alto del Arenal, uno de los emplazamientos más septentrionales del grupo del Alto Duero-TajoJalón vinculados al Celtibérico Antiguo.

\section{PERSPECTIVAS}

La ponderación de los datos recuperados en El Pico abre dos perspectivas distintas. Una, referida al propio yacimiento, establece un potencial interesante para la evidencia arqueológica que aún conserva. Valorar el alcance de las alteraciones era, en efecto, uno de los objetivos de la intervención. La mayoría de ellas ha afectado a un espacio reducido en la zona sur, cerca del borde de la plataforma, donde apenas se conserva potencia estratigráfica. En el resto del cerro se acumulan evidencias (defensas monumentales, estructuras de hábitat, estratigrafía potente) que resultan altamente prometedoras por su estado de conservación y la problemática que anida en su seno.

Otra perspectiva pone en relación los datos arqueológicos con su contexto. Desde nuestro punto de vista, aquellos deben ser contemplados en clave histórica, es decir, como elementos susceptibles de proporcionar información sobre los procesos que los generaron. No obstante, sabedores de las limitaciones de las evidencias recuperadas en El Pico, únicamente consideramos algunas de las perspectivas que ofrecen. El marco cronológico proporcionado por las dataciones abre un debate sobre lo que implican las piezas torneadas en un contexto doméstico tan antiguo. Al confrontar su elevado porcentaje en El Pico con otras evidencias queda sugerida una anomalía que la intervención practicada no permite explicar. Sin embargo, la presencia del torno en ambientes del Celtibérico Antiguo está constatada y ha de ponerse en relación con el marco de relaciones sociales que la promueven.

Las cerámicas a torno se pueden interpretar como elementos exóticos, expresivos de una do- ble vía de relaciones de intercambio documentadas desde los siglos VII-VI a.C.: con los ambientes orientalizantes del mediodía peninsular y con las poblaciones del Valle del Ebro (2), por donde parecen penetrar las primeras producciones, seguramente originales de zonas propiamente ibéricas (Jimeno Martínez y Arlegui Sánchez 1995: 121; Martínez Naranjo 1997: 175; Arenas 1999; Cerdeño 1999: 78). El modo como circulan por las comunidades se relaciona más con dones derivados de intercambios, que con mercancías procedentes del comercio (Cerdeño et al. 1999: 286) (3). Para que esto sea posible ha de darse una serie de circunstancias históricas que lo permitan, las cuales enlazan con la emergencia de las primeras jerarquías en el ámbito del Duero, materializadas en el grupo de los guerreros. Este contexto se puede conceptualizar como un periodo de transición entre dos marcos de relaciones sociales distintos: la sociedad de linajes y la sociedad de clases (Vicent 1998; Burillo y Ortega 1999; Ortega 1999). Dicha transición incorpora, como aspectos relevantes, la consolidación del acceso desigual a los recursos en el seno de las comunidades y la competición por el prestigio adquirido o reforzado a través de la posesión y consumo de ciertos bienes. En este marco la emulación y la incorporación de elementos exóticos, es una práctica habitual. En el territorio ubicado en el Alto Duero-Tajo-Jalón, la transición culminará en la consolidación de sistemas tributarios. En efecto, el fenómeno histórico denominado "celtiberización" no es otro que la aparición y consolidación de la sociedad de clases y, por ende, el Estado en un territorio concreto del centro de la Península Ibérica. En este marco, los indicadores arqueológicos establecen una diferencia entre el sur de la Sierra de Cabrejas y la zona serrana, tal y como apuntan Romero y Lorrio (2011) a pesar de que incluyan a El Pico dentro de los "castros sorianos". En la primera, los restos materiales indican que la "celtiberización" se produce en fechas antiguas mientras que al norte su materialización no se observa hasta mediados del siglo IV cal a.C. Esta dualidad da cuenta, desde nuestro punto de vista, de la coexistencia de dos modelos sociales diferenciados que interactúan positiva o negativamente dentro de este escenario concreto que Burillo y Ortega (1999: 131) ya definieron como "área de

(2) Véase n. 1

(3) Véase n. 1, p. 201. 
fricción". Después de esa fecha, el espacio serrano se incorporó a la formación social clasista. En este proceso se dan trasformaciones de orden socioeconómico que han de tener necesariamente su reflejo arqueológico y cuyo reconocimiento todavía es una labor pendiente.

\section{BIBLIOGRAFÍA}

Alfaro Peña, E. 2005: Castillejos y Villares. Modelos de poblamiento antiguo en el interior del Sistema Ibérico. Asociación Cultural Soria Edita. Soria.

Amaré Tafalla, M. T. y Aguarod Otal, M. C. 1987: "Pervivencia de tradiciones cerámicas celtibéricas en época imperial romana". En I Simposium sobre los Celtíberos (Daroca 1986): 97-140. Zaragoza.

Arenas, J. A. 1999: “Comercio protohistórico: líneas de contacto entre Levante y el Sistema Ibérico". En F. Burillo Mozota (ed.): IV Simposio sobre los Celtíberos. Economía (Daroca 1997): 301-309. Zaragoza.

Bachiller Gil, J. A. 1987: "Los castros del Alto Duero". Anales de prehistoria y arqueología 3: 77-84.

Bachiller Gil, J. A. 1988-1989: "El ajuar material de los castros sorianos". Castrelos 1-2: 109-120.

Bachiller Gil, J. A. 1992: "Hábitat y urbanismo en el sector oriental de la Meseta norte durante el primero milenio antes de Cristo". Vegueta 0: 11-23.

Bachiller Gil, J. A. y Ramírez Sánchez, M. 1993: “Contribución al estudio de los pueblos prerromanos del alto Duero: pelendones". Vegueta 1:31-46.

Barrio, J. y Blasco, M. C. 1989: "Materiales de la II Edad del Hierro procedentes de El Espartal (Madrid)". Cuadernos de Prehistoria y Arqueología de la Universidad Autónoma de Madrid 16: 233-44.

Bellver Garrido, J. A. 1992: "Estudio zooarqueológico de las cabañas circulares de El Castillejo de Fuentesaúco". En II Symposium de Arqueología Soriana (Soria 1989): 325-32. Soria.

Bronk Ramsey, C. 2010: Oxcal Program 4.1.5. http:// c14.arch.ox.ac.uk/embed.php?File $=$ oxcal.html (consulta 27-V-2010).

Burillo Mozota, F. 2007: Los Celtíberos. Etnias y estados. Crítica. Barcelona.

Burillo Mozota, F.; Cano, M. A. y Saiz, M. E. 2008: "La cerámica celtibérica". En D. Bernal Cassasola y A. Ribera i Lacomba (eds.): Cerámicas hispanorromanas. un estado de la cuestión. XXVI Congreso Internacional de la Asociación Rei Cretariae Romanae Fautores (Cádiz. 2008): 171-87. Cádiz.

Burillo Mozota, F. y Ortega Ortega, J. M. 1999: "El proceso de formación de las comunidades campesinas en el Sistema Ibérico 1400-400 a.C.: alguna consideraciones acerca del concepto de "ruptura". En J. A. Arenas Esteban y M. V. Palacios Tamayo (eds.): El origen del mundo celtibérico. Actas de los encuentros sobre el origen del mundo celtibérico (Molina de Aragón 1998): 123-141. Guadalajara.

Carandini, A. 1997: Historias en la Tierra. Manual de excavación arqueológica. Crítica. Barcelona.

Cerdeño, M. L. 1999: "Urbanismo y cultura material en los orígenes de la cultura celtibérica”. En J. A. Arenas Esteban y M. V. Palacios Tamayo (eds.): El origen del mundo celtibérico. Actas de los encuentros sobre el origen del mundo celtibérico (Molina de Aragón 1998): 71-80. Guadalajara.

Cerdeño, M. L. 2008: "El uso de las evidencias materiales en la investigación de la cultura celtibérica: la zona arqueológica de El Ceremeño (Guadalajara)". Trabajos de Prehistoria 65 (1): 93-114.

Cerdeño, M. L. y García Huerta, R. 2001: "Las necrópolis celtibéricas: nuevas perspectivas de estudio". En R. García Huerta y J. Morales Hervás (eds.): $A r-$ queología funeraria: las necrópolis de incineración. Universidad de Castilla-La Mancha. Cuenca: 141-90.

Cerdeño, M. L.; García Huerta, R. y Arenas J. 1995: "El poblamiento celtibérico en la región del alto Jalón y Alto Tajo". En F. Burilllo Mozota (ed.): Poblamiento Celtibérico. III Simposio sobre los Celtíberos (Daroca 1995): 157-178. Zaragoza.

Cerdeño, M. L. y Juez, P. 2002: El Castro Celtibérico de 'El Ceremeño' (Herrería, Guadalajara). Seminario de Arqueología y Etnología Turolense, Junta de Comunidades de Castilla-La Mancha. Teruel.

Cerdeño, M. L.; Sanmartí, E. y García, R. 1999: “Las relaciones comerciales de los Celtíberos". En F. Burillo Mozota (ed.): IV Simposio sobre los Celtíberos. Economía (Daroca 1997): 263-99. Zaragoza.

Eiroa García, J. J. 1979: "Dos fechas de C-14 para la Edad del Bronce en el Alto Duero". Saguntum 14: 39-58.

Eiroa García, J. J. 1980: "Datación por el C-14 del castro hallstático de El Royo (Soria)". Trabajos de Prehistoria 37: 433-42.

Eiroa García, J. J. 1984-1985: “Aportación a la cronología de los castros sorianos". Cuadernos de Prehistoria y Arqueología de la Universidad Autónoma de Madrid 11-12: 197-204.

Escudero Navarro, Z. 1999: "Consideraciones sobre la alfarería vaccea. La producción de la cerámica a Torno". En F. Burillo (ed.): IV Simposio sobre los Celtíberos. Economía (Daroca 1997): 241-257. Zaragoza.

Escudero Navarro, Z. y Sanz Míngez, C. 1999: “Algunas reflexiones a propósito de la llegada del torno cerámico al Valle Medio del Duero". En F. Burillo (ed.): IV Simposio sobre los Celtíberos. Economía (Daroca 1997): 323-340. Zaragoza.

García-Soto Mateos, E. y Rosa Municio, R. de la 1995: "Consideraciones sobre el poblamiento en la ribera soriana del Duero durante la Primera Edad del Hierro". En F. Burilllo Mozota (ed.): Poblamiento Celtibérico. III Simposio sobre los Celtiberos (Daroca 1995): 83-92. Zaragoza.

García Heras, M. 1999: "La artesanía alfarera celtibérica. un reto para la investigación”. En F. Burillo

Trab. Prehist., 70, N. ${ }^{\circ}$ 2, julio-diciembre 2013, pp. 372-384, ISSN: 0082-5638

doi: $10.3989 /$ tp.2013.12120 
(ed.): IV Simposio sobre los Celtíberos. Economía (Daroca 1997): 221-239. Zaragoza.

Gómez Pérez, A. y Sanz Mínguez, C. 1993: “El poblado vacceo de Las Quintanas, Padilla de Duero (Valladolid)". En F. Romero Carnicero, C. Sanz Mínguez y Z. Escudero Navarro (eds.): Arqueología Vaccea. Estudios sobre el mundo prerromano en la Cuenca Media del Duero. Junta de Castilla y León. Valladolid: 335-70.

Harris, E. C. 1991: Principios de estratigrafía arqueológica. Crítica. Barcelona.

Heredero García, R. 1993: "Casas circulares y rectángulares de época vaccea en el yacimiento del Cerro del Castillo (Montealegre)". En F. Romero Carnicero, C. Sanz Mínguez y Z. Escudero Navarro (eds.): Arqueología Vaccea. Estudios sobre el mundo prerromano en la Cuenca Media del Duero, Junta de Castilla y León. Valladolid: 279-302.

Jimeno Martínez, A. 1985: "Prehistoria. La Edad del Hierro". En J. A. Pérez-Rioja (ed.): Historia de Soria, I, Centro de Estudios Sorianos. Soria: 83-122.

Jimeno Martínez, A. 2011: "Las ciudades celtibéricas de la Meseta Oriental". Complutum 22 (2): 223-276.

Jimeno Martínez, A. y Arlegui Sánchez, M. 1995: "El poblamiento en el Alto Duero". En F. Burillo Mozota (ed.): Poblamiento celtibérico. III Simposio sobre los celtíberos (Daroca 1995): 93-126. Zaragoza.

Jimeno Martínez, A. y Martínez Navarro, J. P. 1999: "El inicio de la Edad del Hierro en el nudo hidrográfico Alto Jalón-Alto Duero". En J. A. Arenas Esteban y M. V. Palacios Tamayo (eds.): El origen del mundo celtibérico. Actas de los encuentros sobre el origen del mundo celtibérico (Molina de Aragón 1998): 165-89. Guadalajara.

Lerín Sanz, M. 1999: Ficha del Inventario Arqueológico de Castilla y León. El Pico (Cabrejas del Pinar), Soria. Servicio Territorial de Cultura de la Junta de Castilla y León. Soria.

Liesau, C. y Blasco, M. C. 1999: "Ganadería y aprovechamiento animal". En F. Burilllo Mozota (ed.): IV Simposio sobre los Celtíberos. Economía (Daroca 1997): 119-147. Zaragoza.

López Ambite, F. 2007: "El poblamiento durante el periodo Celtibérico Antiguo en la zona nordeste de la provincia de Segovia: el proceso de jerarquización y concentración de la población". Lucentum XXVI: 23-58.

Lorrio Alvarado, A. J. 1997: Los Celtíberos. Complutum-extra 7, Universidad Complutense. Madrid.

Lorrio Alvarado, A. 2002: "Problemas de cronología en la panoplia celtibérica". En P. Moret y F. Quesada Sanz (eds.): La guerra en el mundo ibérico y celtibérico (ss. VI-II a.C.). Collection Casa de Velázquez 78. Madrid: 65-85.

Mañanes Pérez, T. 2002: Arqueología del Área central de la Cuenca del Río Duero: de Simancas a Coca. Diputación provincial de Valladolid. Valladolid.
Martínez Naranjo, J. P. 1997: "El inicio del mundo celtibérico en el interfluvio Alto Jalón-Mesa”. Complutum 8: 161-82.

Ortega, J. M. 1999: "Al margen de la "identidad cultural": historia social y económica de las comunidades campesinas celtíberas". En F. Burillo Mozota (ed.): IV Simposio sobre los Celtíberos. Economía (Daroca 1997): 417-452. Zaragoza.

Pereira Sieso, J.; Ruiz Taboada, A. y Carrobles Santos, J. 2003: "Aportaciones del C-14 al mundo funerario carpetano: la necrópolis de Palomar de Pintado". Trabajos de Prehistoria 60 (2): 153-168.

Reimer, P. J.; Baillie, M. G. L.; Bard, E; Bayliss, A; Beck, J. W.; Blackwell, P. G.; Bronk Ramsey, C; Buck, C. E.; Burr, G. S.; Edwards, R. L.; Friedrich, M; Grootes, P. M.; Guilderson, T. P.; Hajdas, I; Heaton, T. J.; Hogg, A. G.; Hughen, K. A.; Kaiser, K. F.; Kromer, B; McCormac, F.G.; Manning, S. W.; Reimer, R. W.; Richards, D. A.; Southon, J. R.; Talamo, S.; Turney, C. S. M.; van der Plicht, J.; Weyhenmeyer, C. E. 2009: "IntCal09 and Marine09 Radiocarbon Age Calibration Curves, 0-50,000 Years cal BP". Radiocarbon 51: 1111-1150.

Revilla Andia, M. L. y Jimeno Martínez, A 1986-87: "La dualidad de la cutura castreña en la provincia de Soria”. Zephyrus XXXIX-XL: 87-101.

Romero Carnicero, F. 1984a: "La Edad del Hierro en la serranía soriana: los castros". Boletín del Seminario de Estudios de Arte y Arqueología 50: 27-67.

Romero Carnicero, F. 1984b: "Novedades arquitectónicas de la cultura castreña soriana: la casa circular del castro del Zarranzano". En C. Casa Martínez (ed.): Actas del I Symposium de Arqueología Soriana (Soria 1982): 187-210. Soria.

Romero Carnicero, F. 1984c: "La Edad del Hierro en la provincia de Soria: estado de la cuestión". En C. de la Casa (ed.): Actas del I Symposium de Arqueología Soriana (Soria 1982): 51-124. Soria.

Romero Carnicero, F. 1991: Los Castros de la Edad del Hierro en el Norte de la provincia de Soria. Universidad de Valladolid. Valladolid.

Romero Carnicero, F. 1999: “Origenes y evolución del grupo castreño de la serranía soriana. La aportación de la cronología radiocarbónica". En J. A. Arenas Esteban y M. V. Palacios Tamayo (ed.): Encuentros sobre el origen del mundo celtibérico. Actas de los encuentros sobre el origen del mundo celtibérico (Molina de Aragón 1998): 143-64. Guadalajara.

Romero Carnicero, F. 2005: "Los castros sorianos". En A. Jimeno (ed.): Celtíberos. Tras la estela de Numancia. Diputación Provincial de Soria. Soria: 89-96.

Romero Carnicero, F. y Misiego Tejada, J. C. 1995: "La Celtiberia Ulterior. Análisis del substrato". En F. Burillo Mozota (ed.): Poblamiento Celtibérico. III Simposio sobre los Celtiberos (Daroca 1995): 59-81. Zaragoza. 
Romero Carnicero, F. y Lorrio Alvarado, A. J. 2011: "El origen del poblamiento celtibérico en el Alto Duero". En J. Álvarez Sanchis, A. Jimeno Martínez y G. Ruiz Zapatero (eds.): Aldeas y ciudades en el primer milenio a.C. La Meseta Norte y los orígenes del urbanismo. Complutum 22 (2): 95-127.

Rubinos Pérez, A., Fábregas Valcarce, R., Alonso Mathias, F. y Concheiro Coello, A. (1999): "Las fechas C- 14 del castro de O Achadizo (Boiro, A Coruña): problemática de la calibración de conchas marinas". Trabajos de Prehistoria. 56 (1): 147-55.

Ruiz, A. y Molinos, M. 1992: Los Iberos. Análisis arqueológico de un proceso histórico. Crítica. Barcelona.

Ruiz Zapatero, G. y Lorrio Alvarado, A. 1999: "Las raíces prehistóricas del mundo celtibérico". En J. A. Arenas Esteban y M. V. Palacios Tamayo (eds.): El origen del mundo celtibérico. Actas de los encuentros sobre el origen del mundo celtibérico (Molina de Aragón 1998): 21-36. Guadalajara.

Sacristán de Lama, J. D. 1986: La Edad del Hierro en el Valle Medio del Duero. Universidad de Valladolid. Valladolid.

Sanz Míngez, C. 1997: Los Vacceos: cultura y ritos funerarios de un pueblo prerromano del valle medio del Duero. La necrópolis de Las Ruedas, Padilla de Duero (Valladolid). Monografías. Arqueología en Castilla y León 6, Junta de Castilla y León, Ayuntamiento de Peñafiel. Valladolid.

Schubart, H. 2002-03: "Platos fenicios de occidente". Lucentum XXI-XXII: 25-61.

Seco Villar, M. y Treceño Losada, F. J. 1993: “La temprana 'iberización' de las tierras del sur del Duero a través de la secuencia de 'La Mota', Medina del Campo (Valladolid)". En F. Romero Carnicero, C. Sanz Mínguez y Z. Escudero Navarro (eds.): Arqueología Vaccea. Estudios sobre el mundo prerromano en la Cuenca Media del Duero. Junta de Castilla y León. Valladolid: 133-71.

Tabernero Galán, C.; Sanz Aragonés, A. y Benito Batanero, J. P. 2010: "Necrópolis de cremación en el nordeste de Soria”. En F. Burillo Mozota (ed.): Ritos y Mitos. VI Simposio sobre Celtíberos (Daroca 2008): 391-402. Zaragoza.

Taracena Aguirre, B. 1941: Carta arqueológica de España. Soria. Consejo Superior Investigaciones Científicas. Madrid.

Taracena Aguirre, B. 1954: "Los Celtíberos". En R. Menéndez Pidal (ed.): Historia de España I, III. Espasa- Calpe. Madrid.

Valdés, V. M. 2002: “Análisis químico de los sedimentos, realizado con muestras del castro de 'El Ceremeño’ (Guadalajara)”. En M. L. Cerdeño y P. Juez (eds.): El Castro Celtibérico de 'El Ceremeño' (Herrería, Guadalajara), Seminario de Arqueología y Etnología Turolense. Junta de Comunidades de Castilla-La Mancha. Teruel: 159-67.

Vega Toscano, G. 2002: "Dataciones radiométricas del castro de El Ceremeño". En M. L. Cerdeño y P. Juez (eds.): El Castro Celtibérico de 'El Ceremeño' (Herrería, Guadalajara), Seminario de Arqueología y Etnología Turolense. Junta de Comunidades de Castilla-La Mancha. Teruel: 127-131.

Vicent García, J. M. 1998: “La prehistoria del modo tributario de producción”. Hispania LVIII/3: 823-839.

Trab. Prehist., 70, N. ${ }^{\circ}$ 2, julio-diciembre 2013, pp. 372-384, ISSN: 0082-5638

doi: $10.3989 /$ tp.2013.12120 